\title{
Angiotensin-(1-7)/Mas receptor as an antinociceptive agent in cancer-induced bone pain
}

Brittany L. Forte ${ }^{\mathrm{a}}$, Lauren M. Slosky ${ }^{\mathrm{a}}$, Hong Zhang ${ }^{\mathrm{a}}$, Moriah R. Arnold ${ }^{\mathrm{a}}$, William D. Staatz ${ }^{\mathrm{a}}$, Meredith Hay ${ }^{\mathrm{b}}$, Tally M. Largent-Milnes ${ }^{a}$, Todd W. Vanderah ${ }^{a, \star}$

\begin{abstract}
Many cancerous solid tumors metastasize to the bone and induce pain (cancer-induced bone pain [CIBP]). Cancer-induced bone pain is often severe because of enhanced inflammation, rapid bone degradation, and disease progression. Opioids are prescribed to manage this pain, but they may enhance bone loss and increase tumor proliferation, further compromising patient quality of life. Angiotensin-(1-7) (Ang-(1-7)) binds and activates the Mas receptor (MasR). Angiotensin-(1-7)/MasR activation modulates inflammatory signaling after acute tissue insult, yet no studies have investigated whether Ang-(1-7)/MasR play a role in CIBP. We hypothesized that Ang-(1-7) inhibits CIBP by targeting MasR in a murine model of breast CIBP. 66.1 breast cancer cells were implanted into the femur of BALB/cAnNHsd mice as a model of CIBP. Spontaneous and evoked pain behaviors were assessed before and after acute and chronic administration of Ang-(1-7). Tissues were collected from animals for ex vivo analyses of MasR expression, tumor burden, and bone integrity. Cancer inoculation increased spontaneous pain behaviors by day 7 that were significantly reduced after a single injection of Ang-(1-7) and after sustained administration. Preadministration of A-779 a selective MasR antagonist prevented this reduction, whereas pretreatment with the $A T_{2}$ antagonist had no effect; an $A T_{1}$ antagonist enhanced the antinociceptive activity of Ang-(1-7) in CIBP. Repeated Ang-(1-7) administration did not significantly change tumor burden or bone remodeling. Data here suggest that Ang-(1-7)/MasR activation significantly attenuates CIBP, while lacking many side effects seen with opioids. Thus, Ang-(1-7) may be an alternative therapeutic strategy for the nearly $90 \%$ of patients with advanced-stage cancer who experience excruciating pain.
\end{abstract}

Keywords: Angiotensin 1-7, MasR, Breast, Cancer, Pain, Chronic

\section{Introduction}

Bone pain is experienced by $75 \%$ to $90 \%$ of patients with latestage metastatic cancer. ${ }^{55}$ Metastatic cancer-induced bone pain (CIBP) is frequently reported, but poorly managed. ${ }^{35}$ The World Health Organization recommends mild-to-strong opioids for cancer pain ${ }^{76}$; yet, opioid therapy is associated with several side effects contributing to their failure, ${ }^{48}$ while diversion of prescribed opioids has led to an addiction epidemic. ${ }^{4}$ Recently, reports in humans $^{10,14,60}$ and animals ${ }^{21,72}$ suggest that opioids may exacerbate bone loss, which is counterproductive to antiosteolytic cotherapies and CIBP management. ${ }^{16,47,66,75}$ Disturbingly, recent studies demonstrate an increase in the proliferation/migration of cancers with sustained opioids, ${ }^{15,26,38,80}$ which is the exact

Sponsorships or competing interests that may be relevant to content are disclosed at the end of this article.

a Department of Pharmacology, College of Medicine, University of Arizona, Tucson, AZ, USA, ${ }^{b}$ Department of Physiology, Evelyn McKnight Brain Institute, College of Medicine, University of Arizona, Tucson, AZ, USA

${ }^{*}$ Corresponding author. Address: Department of Pharmacology, College of Medicine, University of Arizona, 1501 N. Campbell Ave, P.O. Box 245050, Tucson, AZ 85724-5050, USA. Tel.: (520) 626-7801. E-mail address: vanderah@email. arizona.edu (T.W. Vanderah).

PAIN 157 (2016) 2709-2721

(C) 2016 International Association for the Study of Pain. This is an open access article distributed under the terms of the Creative Commons Attribution-NonCommercialNoDerivatives License 4.0 (CC BY-NC-ND), which permits downloading and sharing the work provided it is properly cited. The work cannot be changed in any way or used commercially.

http://dx.doi.org/10.1097/j.pain.0000000000000690 condition patients with CIBP experience. Such side effects impede anticancer therapy and diminish patient and family quality of life.

Preclinical modeling of CIBP has revealed mechanisms driving this complex disease state and lead to the identification of potential therapeutic targets. ${ }^{28,63}$ Although the bone is innervated by both sympathetic and nociceptive nerve fibers, many tumors of the bone in humans lack detectable nerve fibers within the tumor and adjacent peripheral bone. ${ }^{31,42}$ Contributors to nociceptive signaling associated with CIBP include an acidic tumor environment and the secretion of growth factors, cytokines, and chemokines from the tumor and tumor-associated cells, as well as enhanced nerve sprouting in the local environment. ${ }^{28,36,39,59}$

The renin-angiotensin system (RAS), well known for its roles in blood pressure regulation and fluid homeostasis, was recently implicated in metastatic bone disease including inflammation, angiogenesis, tumor cell proliferation, and migration. ${ }^{45,61}$ Angiotensin $\|$ (Ang II) is the major end product of the RAS and activates $2 \mathrm{G}$-protein coupled receptors (GPCRs): angiotensin II receptor type $1\left(A T_{1}\right)$ and type $2\left(\mathrm{AT}_{2}\right){ }^{17}$ Physiological effects such as vasoconstriction, inflammation, fibrosis, cellular growth/migration, and fluid retention are reported for $\mathrm{AT}_{1}$ and $\mathrm{AT}_{2} .{ }^{33} \mathrm{Ang} \| \mathrm{I}$ is cleaved by ACE2 to yield angiotensin-(1-7) (Ang-(1-7)), a biologically active heptapeptide. In contrast to Ang II, Ang-(1-7) binds to the GPCR, Mas receptor (MasR; $\mathrm{K}_{\mathrm{d}}=0.83 \mathrm{nM}$ ) with 60- to 100-fold greater selectivity over the $A T_{1}$ and $A T_{2}$ receptors. ${ }^{11,58}$ Activation of the MasR elicits effects opposite to those of the Ang II/AT $1 / \mathrm{AT}_{2}$ axis including anti-inflammation. ${ }^{45,57,58}$

MasR is expressed throughout the central and peripheral nervous systems including the dorsal root ganglion (DRG) and spinal cord. ${ }^{9,41,70}$ In a model of prostaglandin-induced 
hyperalgesia, Ang-(1-7) dose-dependently attenuated peripheral nociception independent from opioid receptors. ${ }^{9,41}$ Ang-(1-7) through MasR reportedly reduces proinflammatory cytokines such as TNF- $\alpha, I F N-\gamma, I L-1 \beta, \quad I L-6$, while increasing the expression of the anti-inflammatory cytokine $\mathrm{IL}-10$ resulting in decreases of PI3K, MAPKs, and JNK signaling in multiple pain models. ${ }^{25,43,67,68}$ Yet, no reports have investigated the efficacy of Ang-(1-7) in clinically relevant cancer pain models, measured bone integrity, or measured tumor burden after sustained administration. Given the efficacy of Ang-(1-7) in inflammatory pain states, we hypothesized that Ang-(1-7) decreases CIBP after acute and chronic administration by targeting MasR in the DRG and femur extrudate.

\section{Materials and methods}

\subsection{In vitro}

\subsubsection{Cell culture}

A murine (female BALB/cfC3H) mammary adenocarcinoma line, 66.1, was a kind gift from Dr. Amy M Fulton. ${ }^{74}$ Cells were cultured in Eagle's minimum essential medium with $10 \%$ fetal bovine serum, $100 \mathrm{IU}^{-1}$ penicillin, and $100 \mu \mathrm{g} / \mathrm{mL}$ streptomycin (P/S). The 66.1 cells were plated in T-75 tissue culture flasks, allowed to grow exponentially in an incubator at $37^{\circ} \mathrm{C}$ and $5 \% \mathrm{CO}_{2}$. The viability of cells cultured with treatments described below was measured using the XTT assay (ATCC, Manassas, VA).

\subsection{In vivo}

\subsubsection{Animals}

All procedures were approved by the University of Arizona Animal Care and Use Committee and conform to the Guidelines by the National Institutes of Health and the International Association for the Study of Pain. Female BALB/cAnNHsd mice (Harlan, Indianapolis, IN) between 15 and $20 \mathrm{~g}$ were used in this study. Mice were housed in a climate control room on a 12-hour light-dark cycle and allowed food and water ad libitum. Animals were monitored on days $0,7,10$, and 14 of the study for clinical signs of rapid weight loss and signs of distress.

\subsubsection{Drug treatment}

Animals received angiotensin-(1-7) (Tocris, Ellisville, MO), the MasR antagonist A-779 (Abcam, Cambridge, MA), the AT antagonist Losartan potassium (Tocris Bioscience, Minneapolis, $\mathrm{MN}$ ), or the $\mathrm{AT}_{2}$ antagonist PD 123319 ditrifluoroacetate (Tocris Bioscience) dissolved in $0.9 \%$ saline. All intraperitoneal (i.p.) injections were made at a volume of $10 \mathrm{~mL} / \mathrm{kg}$. Systemic doses were as follows: Ang-(1-7) = 0 to $100 \mu \mathrm{g} / \mathrm{kg}, \mathrm{A}-779=0.19 \mu \mathrm{g} / \mathrm{kg}$, Losartan potassium $=0.4 \mathrm{mg} / \mathrm{kg}$, PD 123319 ditrifluoroacetate $=$ $0.4 \mathrm{mg} / \mathrm{kg}$. In antagonist studies, A-779, Losartan potassium, or PD 123319 ditrifluoroacetate was administered 30 minutes before Ang-(1-7).

\subsubsection{Tail flick}

A warm water $\left(52^{\circ} \mathrm{C}\right)$ tail flick test was used to determine the effects of Ang-(1-7) on acute nociception. The distal third of the tails of naive mice were submerged into the water bath. The withdraw latency, defined as the time for the tail to be withdrawn from the water bath, was recorded. A cutoff time of 10 seconds was enforced to prevent tissue damage. Baseline latencies were recorded before drug administration. Animals were dosed (i.p.) with Ang-(1-7) $(0-100 \mu \mathrm{g} / \mathrm{kg})$. Tail flick latencies were reassessed $15,30,60,90,120,150$, and 180 minutes after treatment.

\subsubsection{Rotarod}

A rotarod performance test was used to determine the motor and/or sedative effects of Ang-(1-7) (Rotamex 4/8; Columbus Instruments, Columbus, $\mathrm{OH})$. Three days before testing, naive mice were subjected to 5 trials in which they were able to acclimate to the rotating rod $\left(10 \mathrm{rpm}^{71}\right)$. On the day of testing, animals were allowed one trial and then baselined. The amount of time the animal remained on the rod was recorded, with a cutoff time of 120 seconds to prevent exhaustion. Animals were dosed (i.p.) as previously described and reevaluated 15, 30, 60, and 120 minutes after administration.

\subsubsection{Arthrotomy: intramedullary implantation of 66.1 cells}

To induce CIBP, an arthrotomy was performed, as previously described. ${ }^{28}$ Briefly, animals were anesthetized with $80 \mathrm{mg} / \mathrm{kg}$ ketamine to $12 \mathrm{mg} / \mathrm{kg}$ xylazine (in a $10 \mathrm{~mL} / \mathrm{kg}$ volume). The surgical area was shaved and cleaned with $70 \%$ ethanol and betadine. The condyles of the right femur were exposed and a burr-hole $(0.66 \mathrm{~mm})$ was drilled to create a space for the 66.1 cell inoculation. A $5-\mu \mathrm{L}$ volume of 66.1 cells (8000 cells per $1 \mu \mathrm{L}$ ) in minimum essential medium (or $5 \mu \mathrm{L}$ minimum essential medium without cells in sham animals) was injected into the intramedullary space of the mouse femora. Proper placement of the injector was confirmed by radiograph (Faxitron $\mathrm{X}$-ray imaging). Holes were sealed with bone cement and the patella reset. Muscle and skin were closed in separate layers with 50 vicryl suture and wound autoclips, respectively. Animals were given $8 \mathrm{mg} / \mathrm{kg}$ (10 mL/kg volume) gentamicin to prevent infection. Staples were removed 7 days after surgery.

\subsubsection{Acute behavioral testing}

Fourteen days after surgery, baseline behaviors of spontaneous flinching/guarding were recorded. Flinching was characterized by the lifting and rapid flexing of the hind paw ipsilateral to femoral inoculation when not associated with walking or other movement. Guarding was characterized by lifting the inoculated hind limb into a fully retracted position under the torso. Both flinching and guarding of the inoculated limb are accurate measurements of ongoing pain and is similar to what is observed clinically in patients with bone cancer who hold or move their cancer-bearing limb away from sensory stimuli. ${ }^{30,54}$ The total number of flinches and the time spent guarding 2-minute duration was recorded. Mice were then separated into treatment groups and dosed systemically with Ang-(1-7) (0-10 $\mu \mathrm{g} / \mathrm{kg}$, i.p.), A-779 (0.19 $\mu \mathrm{g} / \mathrm{kg}$, i.p.), Losartan potassium (0.4 mg/kg, i.p.), PD 123319 (0.4 mg/kg, i.p), ${ }^{44}$ vehicle (0.9\% saline, i.p.), or a combination of Ang-(1-7) and each antagonist. Antagonists were administered 30 minutes before Ang-(1-7). After administration, animals were tested at over a 3-hour time course until their pain behaviors returned to baseline.

\subsubsection{Chronic behavioral testing}

Seven days after surgery, baseline behaviors of spontaneous pain, as described above, were recorded. Mice were treated (i.p.) with Ang-(1-7) $(0.058 \mu \mathrm{g} / \mathrm{kg})$, A-779 $(0.19 \mu \mathrm{g} / \mathrm{kg})$, vehicle $(0.9 \%$ saline), or a combination. The antagonist was administered 30 minutes before Ang-(1-7). Animals were dosed at the same time each day 7 to 14 days after surgery. On day 10, pain behaviors 
were assessed 15 minutes after treatment, based on the time of peak effect determined by the acute studies. Fourteen days after surgery, behaviors were again recorded before and after treatment. Animals were killed after treatment and testing on postsurgery day 14, and the following tissues were collected for biochemical analyses: serum, femur extrudate, and lumbar DRG.

\subsubsection{Mechanical hypersensitivity}

The assessment of mechanical hypersensitivity was determined by measuring the withdrawal threshold of the paw ipsilateral to the site of nerve injury in response to probing with a series of calibrated von Frey filaments (0.04-4.0 g). Before femur innoculation, female mice were tested for preinjury baseline mechanical sensitivity. Filaments were applied perpendicularly to the plantar surface of the right hind paw of mice while in individual plexiglass chambers suspended on a wire-mesh. Animal's mechanical threshold was reassessed 7 days after femur inoculation with either media containing 66.1 cells or media only for a new injury-induced baseline. To determine whether Ang-(1-7) attenuates CIBP, the animals' mechanical threshold was reassessed on days 7,10 , and 14 (after femur inoculation) 30 minutes after Ang-(1-7) or vehicle administration. The withdrawal threshold was determined by sequentially increasing and decreasing the stimulus strength ("up-down" method) analyzed using a Dixon nonparametric test $^{34}$ and expressed as the mean withdrawal threshold. Animals' mechanical thresholds were then assessed.

\subsubsection{Nesting}

Nesting behaviors of naive, media, and cancer-inoculated mice were assessed using the protocol described by Negus et al. ${ }^{40}$ Animals were acclimated to individual cages, without an existing nest, for 30 minutes before drug administration. Cotton fiber Nestlets were cut into 6 equal pieces, and each piece was placed in the cage in 6 zones in the manner previously described after drug administration. Throughout the duration of the 100-minute time course, the number of cleared zones was recorded; upon completion, the height ( $\mathrm{mm}$ ) of each fluffed Nestlet was measured.

\subsection{Ex vivo}

\subsubsection{Western blot analysis}

Dorsal root ganglia and femur extrudates from mice used in behavioral studies were analyzed for expression of MasR. The DRG were homogenized in modified radioimmunoprecipitation assay buffer with protease inhibitor cocktail and EDTA (Pierce, Rockford, IL) through sonication. Then, $10 \mu \mathrm{g}$ of each sample was resolved on 10\% SDS-polyacrylamide gels (TGX Criterion XT; BioRad, Hercules, CA) and transferred to a polyvinylidene difluoride membrane (BioRad). Ipsilateral and contralateral femurs were removed from each animal. For each femur, the proximal and distal ends were clipped and the intramedullary extrudate was flushed 6 times with $700 \mu \mathrm{L}$ phosphate-buffered saline containing protease inhibitor cocktail and EDTA (Pierce). Femur marrow from 5 animals was pooled per sample, and $15 \mu \mathrm{g}$ of sample was resolved and transferred in the same manner as of DRG. Protein transfer was verified by staining blots with Ponceau S (Sigma, St. Louis, MO), and polyvinylidene difluoride membranes were blocked with $5 \%$ nonfat dry milk in Tris-buffered saline containing $0.05 \%$ (vol/vol) Tween-20 (TBST) for 1 hour at room temperature. Membranes were then incubated with primary antibody: rabbit polyclonal anti-angiotensin-(1-7) Mas Receptor (Alomone Labs AAR-013; 1:200 dilution for DRG or 1:800 for femurs) or mouse monoclonal anti-actin AC40 (Cell Signaling 7076S; 1:4000 dilution) in 1\% milk in TBST overnight at $4^{\circ} \mathrm{C}$. The membranes were washed in TBST and incubated with appropriate secondary antibodies (Cell Signaling 7074 Anti-rabbit IgG HRP-Linked, 1:10,000 dilution; Cell Signaling 7076 Anti-mouse IgG HRP-Linked, 1:5000 dilution) for 1 hour at room temperature. Membranes were again washed and developed using enhanced chemiluminescence (Clarity ECL Substrate, BioRad), and bands were detected using GeneMate Blue-Ultra Autorad films (BioExpress, Kaysville, UT). Bands were quantitated and corrected for background using ImageJ densitometric software (Wayne Rasband, Research Services Branch, National Institute of Mental Health, Bethesda, MD). All data were normalized to actin in each lane and reported as fold change over untreated control.

\subsubsection{Data analysis and statistical procedures}

\subsubsection{Behavioral}

Statistical significance between treatment groups for the doseresponse curve in acute behavioral studies was determined by 1-way analysis of variance (ANOVA) and the Tukey $t$ test for unpaired experimental data. Statistical significance between treatment groups for chronic behavioral studies was determined using 2-way ANOVA and the Tukey $t$ test for multiple comparisons. Data are reported as mean \pm SEM for $n=8$ to 12 mice/treatment group. Power analyses were performed on cumulated data by using G*Power3.1 software to estimate the optimal numbers required. We found that adequate statistical separation requires the group size of 8 to 12 per behavioral test to detect differences (80\%) between the drugs and control groups at alpha $<0.05$. The experimenter was blinded to drug vs vehicle treatments.

\subsubsection{Ex vivo}

Western blot data are reported as a mean \pm SEM from 3 to 5 groups of $n=3$ to 5 animals. Statistical significance between treatment groups for the carboxy-terminal collagen crosslinks (CTX), radiograph, and hematoxylin and eosin data was determined by 1-way ANOVA and the Tukey $t$ test for unpaired experimental data. The CTX data are reported as mean \pm SEM for $n=4$ mice/treatment group. Radiograph data are reported as mean \pm SEM for $n=5$ to 11 mice/treatment group. Hematoxylin and eosin data are reported as mean \pm SEM for $n=3$ to 5 mice/ treatment group.

\subsubsection{General}

Power analyses were conducted based on the pilot data and historical data using $\mathrm{G}^{\star}$ Power3.1 software to efficiently detect significant differences among groups. The effect size was estimated from the data obtained from our historical studies. An a priori computation for 1-way ANOVA was used to estimate size given alpha $=0.05$ and power set to 1 -beta $=0.95 . P<0.05$ was accepted as statistically significant. Statistical analyses were run and plots were generated in GraphPad Prism 5.0 (Graph Pad Inc, San Diego, CA).

\section{Results}

3.1. Ang-(1-7) administration in established cancer-induced bone pain attenuates spontaneous and evoked pain

We assessed the antinociceptive efficacy of Ang-(1-7) in a model of established CIBP in which 66.1 tumor cells were injected into 
the right femurs of syngeneic BALB/CAnNHsd mice. Before surgery, mice did not display behavioral signs of pain; yet 14 days after cancer inoculation surgery, animals present with a significant amount of flinching and guarding compared with media-treated controls $(P<0.0001, \mathrm{n}=8$ ) (Fig. 1A, C). A single systemic injection of Ang-(1-7) (0.036, 0.360, 1, and $10 \mu \mathrm{g} / \mathrm{kg})$ or vehicle was administered, and pain behaviors were assessed. Animals given an acute i.p. administration of Ang-(1-7) showed a significant $(P<0.01, \mathrm{n}=8$ ) reduction in spontaneous pain behaviors with an onset 15 minutes after injection of either 0.36 or $1 \mu \mathrm{g} / \mathrm{kg}$, which persisted for nearly 2 hours (Fig. 1A, C). Dose-response curves were constructed from data collected at the time of peak effect, 15 minutes (Fig. 1B, D). At 15 minutes, the maximum effect of Ang-(1-7) in reducing guarding behavior was $52.75 \%$ $(P<0.01, \mathrm{n}=8)$ with a corresponding $A_{90}$ dose of $0.058 \mu \mathrm{g} / \mathrm{kg}$ (Fig. 1B). Flinching displayed less of a dose dependency and a more significant inhibition at the lower dose $(0.036 \mu \mathrm{g} / \mathrm{kg})$. Thus, a single injection of Ang-(1-7) is effective in reducing
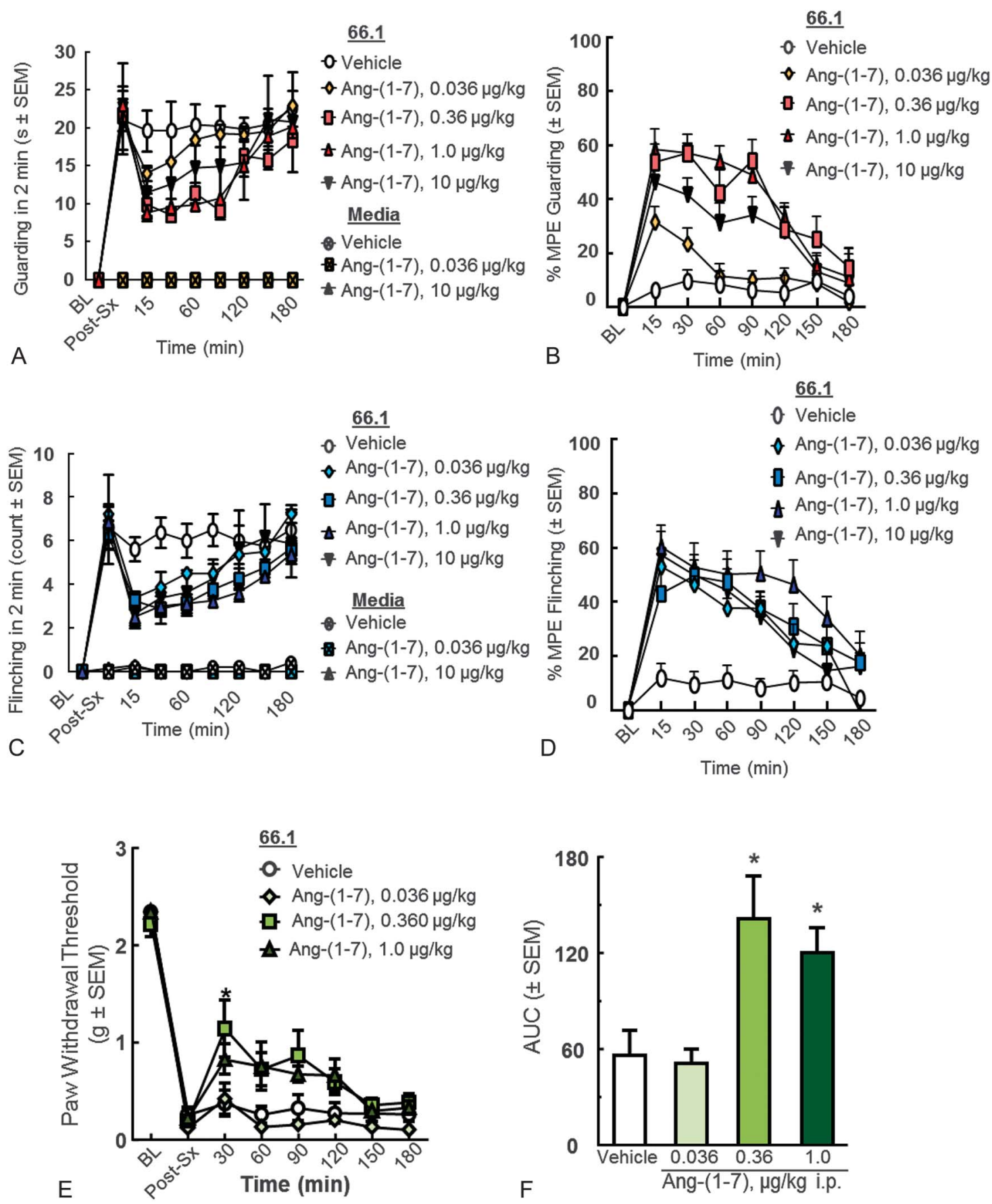

Figure 1. Ang-(1-7) administration in established cancer-induced bone pain attenuates spontaneous pain. Spontaneous pain behaviors (A) guarding and (C) flinching were recorded in a 2-minute period 14 days after inoculation and at various time points after drug administration. Time of peak effect at 15 minutes after administration ( $P<0.01$ for 0.36 and $1 \mu \mathrm{g} / \mathrm{kg}$, compared with saline) lasting 2 hours. (B) $E_{\max }=52.75 \%, A_{90}=0.058 \mu \mathrm{g} / \mathrm{kg}$ for the guarding curve, (D) $A_{90}=1 \mu \mathrm{g} /$ $\mathrm{kg}$ for the flinching curve. Tactile allodynia was measured 14 days after inoculation and at various time points after drug administration; a significant $(P<0.05$, $\mathrm{n}=8$ ) reduction in evoked pain behaviors with an onset 30 minutes was measured after injection of 0.360 and $1 \mu \mathrm{g} / \mathrm{kg}$ and persisted for nearly 2 hours (E). Area under the curve was calculated (F). Values represent mean $\pm \mathrm{SEM}, \mathrm{n}=8$ per group. 
spontaneous pain behavior by more than $50 \%$ in animals with established CIBP.

Furthermore, mechanical hypersensitivity was measured through the use of von Frey filaments. Before femur inoculation surgery, animals displayed the highest level of paw withdrawal threshold measurable by the filaments; however, this threshold was significantly reduced 14 days after femur inoculation (Fig. 1E). For acute testing, a single systemic injection of Ang(1-7) or vehicle was administered, and pain behaviors were assessed at 30-minute intervals after injection (Fig. 1E). Animals given an acute i.p. administration of Ang-(1-7) showed a significant $\left({ }^{\star} P<0.05, \mathrm{n}=8\right.$ ) reduction in evoked pain behaviors with an onset 30 minutes after injection of either 0.360 and $1 \mu \mathrm{g} / \mathrm{kg}$, which persisted for nearly 2 hours (Fig. 1E). Area under the curve was calculated at the time of peak effect (30 minutes after administration) ( $\left.{ }^{\star} P<0.05, \mathrm{n}=8\right)$ (Fig. 1F). Together, these data suggest that one-time administration of Ang-(1-7) reduces both spontaneous and evoked pain responses in established CIBP.

\subsection{Effects of MasR/AT $/ A T_{2}$ antagonists on Ang-(1-7) antinociception in established cancer-induced bone pain}

To investigate the receptor dependence of Ang-(1-7), A-779 $(0.19 \mu \mathrm{g} / \mathrm{kg})$, the selective MasR antagonist, or vehicle, was administered 30 minutes before Ang-(1-7) (0.058 $\mu \mathrm{g} / \mathrm{kg}) 14$ days after femur inoculation. Spontaneous pain behaviors of flinching and guarding were recorded 15, 30, 60, 90, 120, and 150 minutes after administration until animal's pain behaviors returned to baseline, after 150 minutes. Inhibition of MasR with A-779 alone did not alter spontaneous or evoked pain thresholds; however, pretreatment with A-779 significantly inhibited Ang-(1-7) attenuation of guarding (Fig. 2A, $P<0.01$ ) and flinching (Fig. 2B, $P<0.001$ ). These data suggest that Ang$(1-7)$ elicits antinociception in established CIBP through actions at MasR.

Because Ang II is the precursor molecule to Ang-(1-7), we next investigated whether the effects of Ang-(1-7) in animals with established CIBP were mediated by the Ang II receptors. Pretreatment with selective antagonists to $A T_{1}$ and $A T_{2}$, Losartan potassium $\left(\mathrm{K}_{\mathrm{i}}=10 \mathrm{nM}^{6}\right)$ and PD 123319 (also known as EMA200) $\left(\mathrm{IC}_{50}=34 \mathrm{nM}^{5}\right)$, respectively, was performed before Ang-(1-7) administration. Animals were inoculated with 66.1 cells or media, as previously described, and pain behaviors were assessed 14 days after femur inoculation. Mice received either the $A T_{1}$ or $A T_{2}$ antagonist $(0.4 \mathrm{mg} / \mathrm{kg}$, i.p.) 30 minutes before Ang-(1-7) $(0.058 \mu \mathrm{g} / \mathrm{kg}$, i.p.), or vehicle $(0.9 \%$ saline). In accordance with the above study, Ang-(1-7) administration alone reduced pain behaviors $(P<0.01, \mathrm{n}=$ 7), whereas neither Losartan potassium nor PD 123319 significantly altered pain behaviors when administered on their own. Interestingly, administration of the $\mathrm{AT}_{1}$ receptor antagonist, Losartan potassium, before Ang-(1-7) yielded a $77.527 \%$ maximal possible efficacy (MPE) in reducing guarding $(P<$ $0.0001, n=7) 30$ minutes after administration (Fig. 2C) and an 80.56\% MPE in reducing flinching $(P<0.0001, \mathrm{n}=7) 15$ minutes after administration (Fig. 2D). However, use of the $A_{2}$ antagonist, PD 123319, before Ang-(1-7) did not further increase, nor did it decrease guarding or flinching of animals with established CIBP (Fig. 2E, F) as compared with the animal group treated with solely Ang-(1-7). Together, these data suggest that the actions of Ang-(1-7) in reducing CIBP are mediated largely through MasR, with some action through the $A T_{1}$ receptor.

\subsection{Antinociceptive effects of Ang-(1-7) through MasR are maintained after repeated administration}

Because sustained administration of many analgesics can lead to the development of tolerance, we examined whether Ang-(1-7) retained antinociceptive activity against CIBP after repeated administration. Ang-(1-7) (0.058 $\mu \mathrm{g} / \mathrm{kg}$, i.p.) was administered daily, beginning 7 days after implantation of 66.1 cells into the femur. Mice were evaluated for CIBP spontaneous pain behaviors on day 7 before drug administration, and on days 10 and 14 after surgery 15 minutes after treatment. Cancer inoculation significantly increased the amount of time spent guarding and number of flinches after surgery $(P<0.0001, \mathrm{n}=12)$. Animals experienced significant $(P<0.0001, \mathrm{n}=12)$ reduction in guarding (Fig. 3A) and flinching (Fig. 3B) after Ang-(1-7) treatment on days 10 and 14 after surgery. Vehicle treatment had no significant effect.

Additionally, sustained administration of Ang-(1-7) $(0.058 \mu \mathrm{g} /$ $\mathrm{kg}$, i.p.) had a similar effect on evoked pain response. Cancer inoculation significantly reduced paw withdrawal thresholds 7 days after surgery $(P<0.05, \mathrm{n}=12)$. Animals experienced significant $(P<0.05, \mathrm{n}=12)$ increase in the paw withdrawal threshold (Fig. 3E) after Ang-(1-7) treatment on day 14 after surgery but did not achieve significance on day 10. Vehicle treatment had no significant effect. Together, these data suggest that sustained administration of Ang-(1-7) reduces both spontaneous and evoked pain responses in established CIBP on day 14.

To determine whether MasR continued to underlie actions of Ang-(1-7) after repeated dosing, A-779 (0.19 $\mu \mathrm{g} / \mathrm{kg})$ was administered 30 minutes before Ang-(1-7) $(0.058 \mu \mathrm{g} / \mathrm{kg})$ daily 7 to 14 days after cancer inoculation (Fig. 3C, D). Administration of A-779 alone had neither a pronociceptive nor an antinociceptive effect on the mice, and similar to our observations after a single injection, the chronic pretreatment with A779 before Ang-(1-7) prevented attenuation of CIBP by the latter. Together, these data suggest that the reduction in pain behaviors associated with CIBP by repeated dosing of Ang-(1-7) is mediated through MasR.

\subsection{Ang-(1-7) administration in established cancer-induced bone pain does not change nesting behaviors}

Nesting, an innate behavior in mice, has been shown to be hindered by various states of pain. ${ }^{40}$ Thus, we evaluated the effects of both the arthrotomy and administration of Ang-(1-7) on nesting behavior. Six equally sized pieces of Nestlet were placed into 6 zones of the animals' individual cages. The number of zones that the animals cleared of the Nestlet pieces was recorded over the 100-minute time course (Fig. 4A). During the first hour of the study, the 66.1-inoculated animals, day 6 after surgery, cleared significantly fewer zones than did the naive animals $(P<$ 0.05). After the second hour of the study, the media animals cleared fewer zones than did both the naive and 66.1-inoculated animals $(P<0.05)$. A second study was conducted in which 66.1-inoculated animals, day 15 after surgery, were treated with Ang-(1-7) $(0.058 \mu \mathrm{g} / \mathrm{kg}$, i.p.) or vehicle (0.9\% saline) (Fig. 4B). The nesting behaviors of both treated cancerous groups did not differ significantly from the naive group. However, at both the 75- and 90-minute time points, the media animals cleared fewer zones than did the other groups $(P<0.05)$. These data demonstrate that although the nesting of animals with established CIBP alters the nesting behaviors of mice, Ang-(1-7) administration does not further alter these behaviors. 


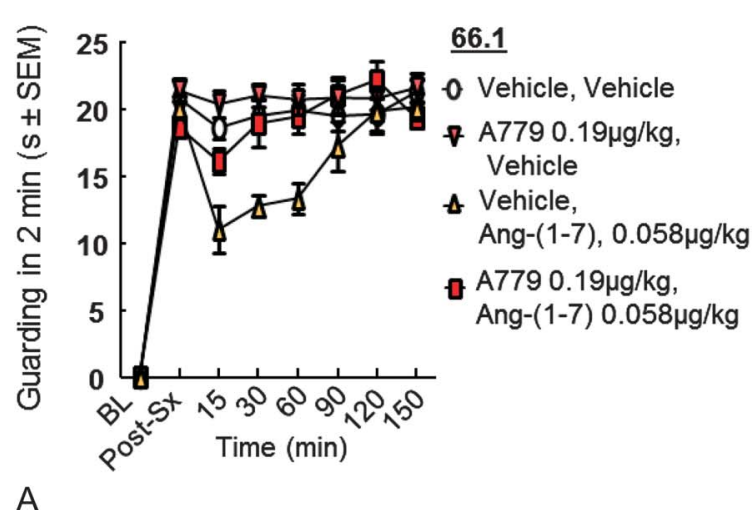

A

$\underline{66.1}$

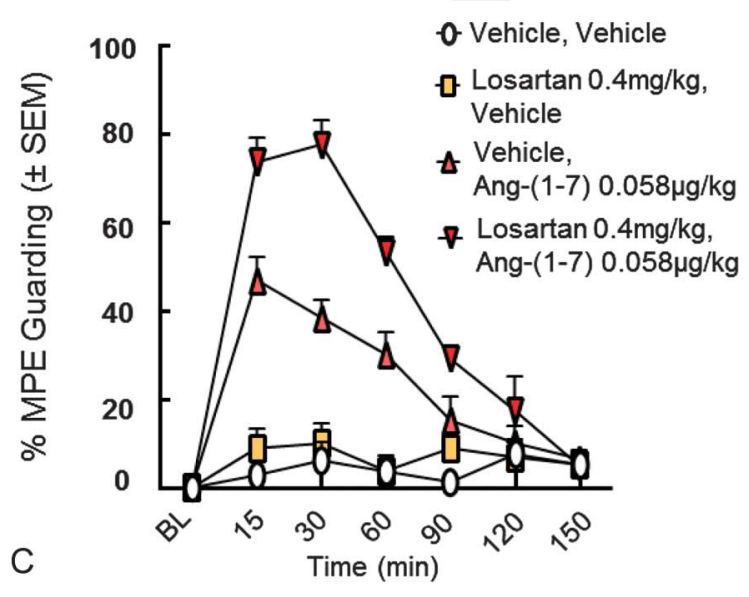

$\underline{66.1}$

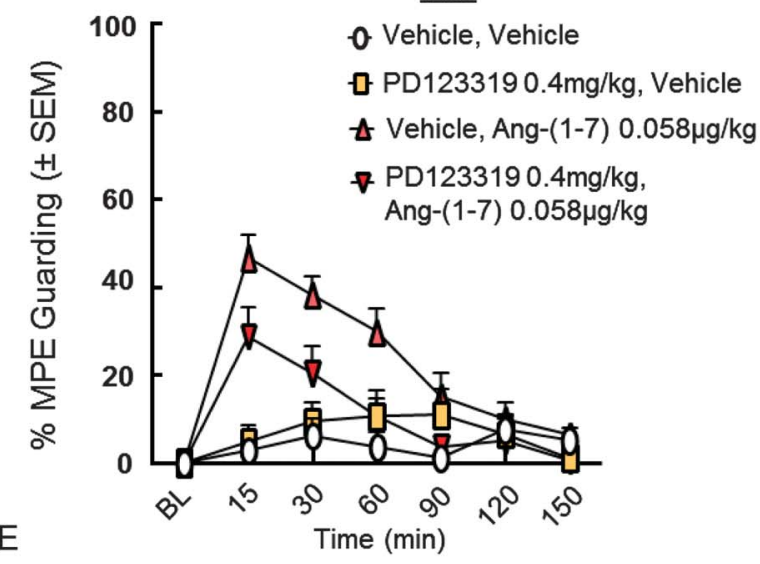

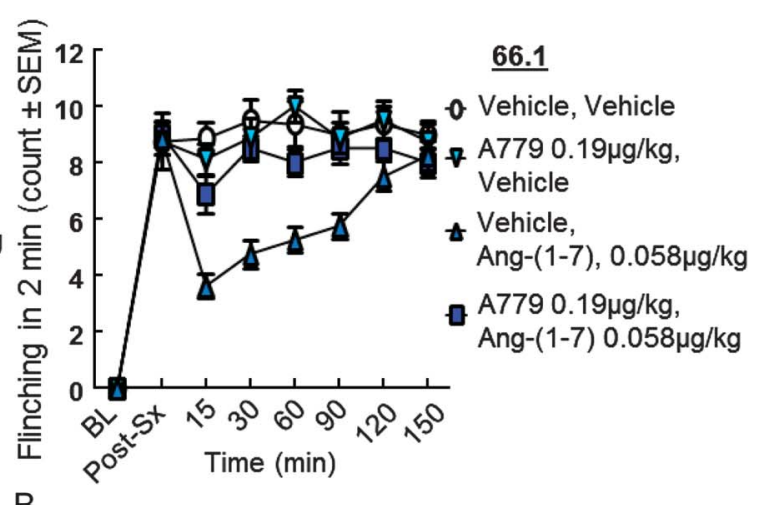

$\underline{66.1}$

0 Vehicle, Vehicle

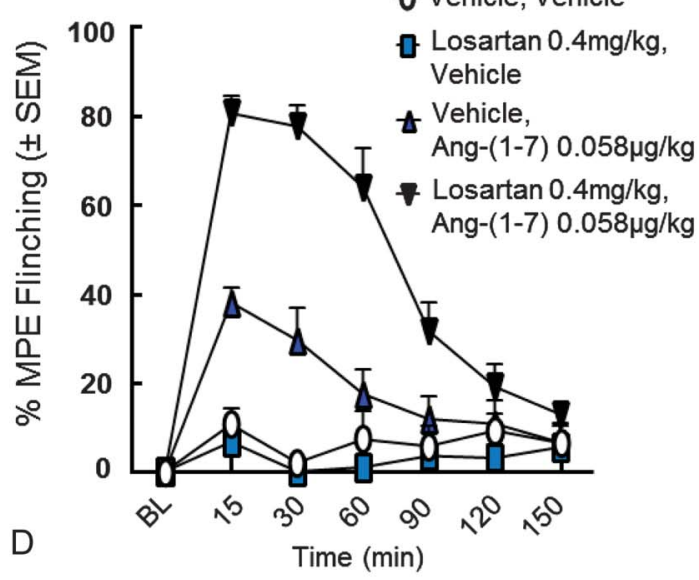

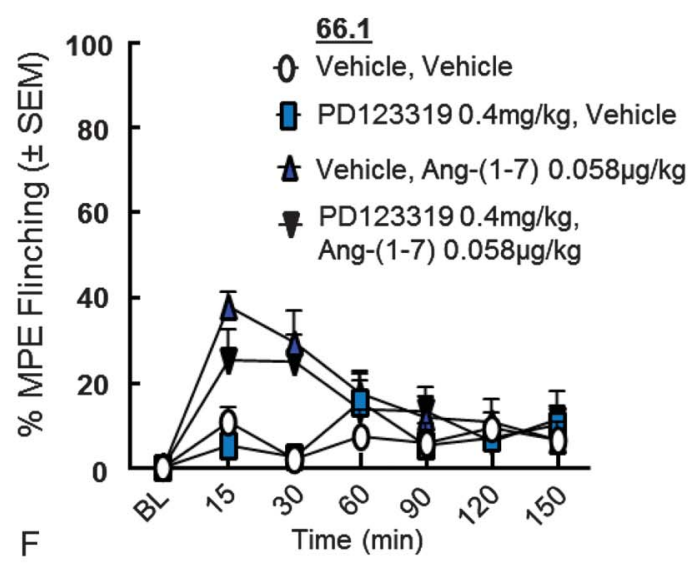

Figure 2. Effects of MasR/AT $/ A T_{2}$ antagonists on Ang-(1-7) antinociception in established cancer-induced bone pain (CIBP). Spontaneous pain behaviors guarding (A, C, and E) and flinching (B, D, and F) were recorded as previously described. A-779 (A and B), Losartan (C and D), and PD 123,319 (E and F) did not significantly alter spontaneous pain behaviors when administered alone. Administration of A-779 (0.19 $\mu \mathrm{g} / \mathrm{kg}$, i.p.) 30 minutes before Ang-(1-7) completely reversed the effects of Ang-(1-7) on guarding (A) and flinching (B) in the CIBP model, suggesting that the Ang-(1-7) works at MasR to reduce CIBP. Losartan potassium (0.4 mg/kg, i. p.), administered 30 minutes before Ang-(1-7), yielded a $77.527 \%$ maximal possible efficacy in reducing guarding $(P<0.0001) 30$ minutes after administration $(C)$ and an $80.563 \%$ reduction in flinching $(P<0.0001) 15$ minutes after administration (D). Use of PD $123,319(0.4 \mathrm{mg} / \mathrm{kg}$, i.p.) $30 \mathrm{minutes}$ before Ang-(1-7) did not alter guarding or flinching of animals with established CIBP ( $E$ and F) as compared with the animal group treated with solely Ang-(1-7). Values represent mean $\pm \mathrm{SEM}, \mathrm{n}=7$ to 8 per group.

\subsection{Ang-(1-7) administration results in antinociception but not motor impairment in naive mice}

Previous studies have indicated that Ang-(1-7) has limited antinociceptive efficacy in noninjured animals after peripheral administration using a mechanical force test to the hind paw. ${ }^{8} \mathrm{We}$ administered Ang-(1-7) systemically (0.360, 1, $10 \mu \mathrm{g} / \mathrm{kg}$, i.p.) in naive mice and observed a small but significant increase in thermal tail flick latencies. Ang-(1-7) effects peaked between 15 and 30 minutes after administration with $1 \mu \mathrm{g} / \mathrm{kg}$ Ang-(1-7) (MPE = $27.8 \%, P<0.001)$ and $10 \mu \mathrm{g} / \mathrm{kg}$ Ang-(1-7) $(\mathrm{MPE}=20.2 \%, P<0.01)$ that returned to baseline between 90 and 120 minutes.

To exclude the possibility that Ang-(1-7) administration reduced mobility to increase tail withdraw latency, rotarod testing was performed. Naive animals were trained to walk on a rotating 

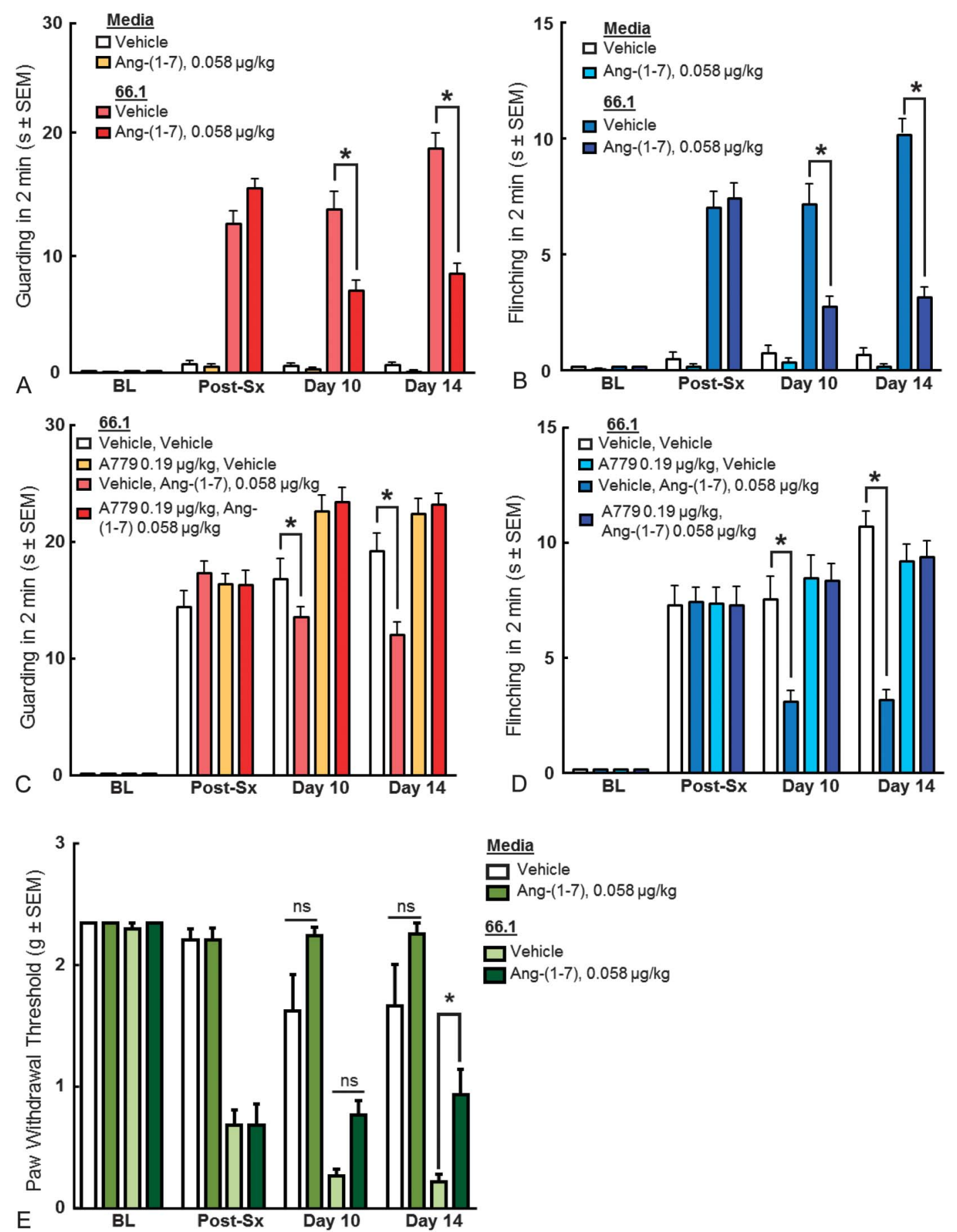

Figure 3. Antinociceptive effects of Ang-(1-7) through MasR are maintained after repeated administration. Spontaneous pain behaviors guarding (A) and flinching (B) were recorded in a 2-minute period before surgery, after surgery (7 days after inoculation), and after drug administration on days 10 and 14 . Daily administration of Ang-(1-7) $(0.058 \mu \mathrm{g} / \mathrm{kg}$, i.p.) significantly reduced spontaneous pain behaviors associated with cancer-induced bone pain (CIBP) $(P<0.0001)$. Furthermore, tactile allodynia was recorded before surgery, after surgery (7 days after inoculation), and after drug administration on days 10 and 14 . Cancer inoculation significantly reduced paw withdrawal thresholds 7 days after surgery $(P<0.05, n=12)$. To investigate receptor dependence, animals were dosed postsurgery days 7 to 14 with A-779 $(0.19 \mu \mathrm{g} / \mathrm{kg}$, i.p.) 30 minutes before administration of Ang-(1-7). Spontaneous pain behaviors guarding (C) and flinching (D) were recorded as previously described. Daily administration of A-779 reversed the effects of Ang- $(1-7)$ in the CIBP model. Animals experienced significant $(P<0.05, n=12)$ increase in the paw withdrawal threshold (E) after Ang-(1-7) treatment on postsurgery day 14. Values represent mean \pm SEM, $n=12$ per group.

rod for 2 minutes. After training, mice were injected with Ang-(1-7) by either spinal $(0.3 \mathrm{pmol} / 5 \mu \mathrm{L})$ or systemic routes $(0.058$ and 10 $\mu \mathrm{g} / \mathrm{kg})$. No significant differences in rotarod latencies were observed between vehicle- and Ang-(1-7)-treated mice (results not shown; $P=0.99$ i.t.; $P=0.18$ i.p.). Together, these data suggest that systemic Ang-(1-7) is antinociceptive after a single administration without noticeable impact on motility.

\subsection{MasR is expressed in the dorsal root ganglion and femur extrudate}

Our findings that Ang-(1-7)/MasR alleviates CIBP suggest that MasR is expressed within pain pathways and within the bone tumor microenvironment. We collected the ipsilateral lumbar DRG and femur extrudate from naive, sham, cancer (66.1), and 

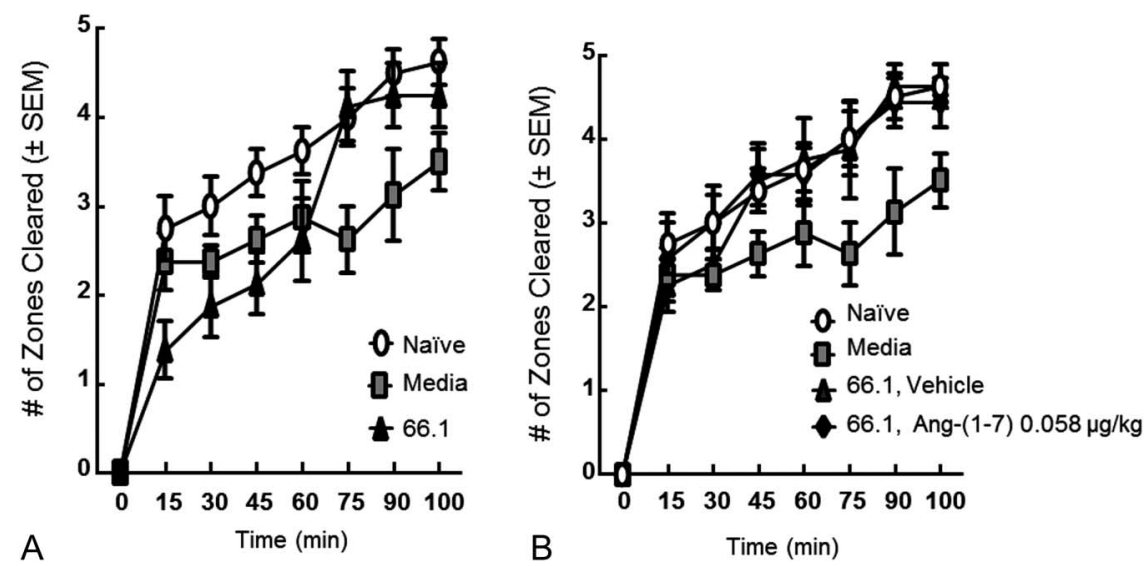

Figure 4. Ang-(1-7) administration in established cancer-induced bone pain does not change nesting behaviors. Nesting, an innate behavior of mice, was studied. During the first hour of the study, the 66.1-inoculated animals, on postsurgery day 6, cleared significantly $(P<0.05)$ fewer zones than did naive animals (A). After the second hour of the study, the media animals cleared fewer zones than did both the naive and 66.1-inoculated animals $(P<0.05)$. A second study was conducted in which 66.1-inoculated animals, on postsurgery day 15, were treated with Ang-(1-7) $(0.058 \mu \mathrm{g} / \mathrm{kg}$, i.p.) or vehicle $(0.9 \%$ saline) (B). The nesting behaviors of both cancerous groups did not differ significantly from that of the naive group. At both 75- and 90-minute time points, media animals cleared fewer zones than did the other 3 groups $(P<0.05)$. Values represent mean $\pm \mathrm{SEM}, \mathrm{n}=8$ per group.

66.1 Ang-(1-7)-treated mice. In naive BALB/cAnNHsd mice, MasR is expressed in the DRG (Fig. 5A); MasR bands were observed at $\sim 50$ and $\sim 40 \mathrm{kDa}$. Sham surgery (ie, media only) did not significantly alter MasR expression levels in the DRG. Introduction of the murine mammary adenocarcinoma line 66.1 into the femoral intramedullary space did not significantly alter MasR expression in ipsilateral DRG. MasR was also found to be expressed in the femur extrudates of the same mice (Fig. 5C), and cancer inoculation significantly increased the expression of MasR in the femur extrudate at both $\sim 50$ and $\sim 40 \mathrm{kDa}(P<$ 0.001 compared with the sham group), whereas sham surgery did not significantly alter the expression of MasR in the femur extrudate as compared with the naive animal group (Fig. 5D).

\subsection{Repeated dosing of Ang-(1-7) does not alter tumor burden of mice with established cancer-induced bone pain or alter cell viability in vitro}

To determine whether repeated Ang-(1-7) administration altered tumor burden in mice with established CIBP as a means of reducing the pain behaviors associated with the disease. After chronic administration studies, femurs were harvested from animals, decalcified, and embedded in paraffin blocks before sectioning $(5 \mu \mathrm{m})$ and hematoxylin and eosin staining (Fig. 6A). The region of the bone containing cancer cells was quantified as a measure of total intramedullary content and represented as a percent of the entire cells within the bone. Repeated Ang-(1-7) administration did not significantly increase, nor did it decrease the percent tumor of the bone $(P=0.3, \mathrm{n}=3-5)$ as compared with the saline-treated group (Fig. 6B). Thus, repeated Ang-(1-7) administration did not significantly impact tumor burden within the femur.

To verify in vivo findings, we assessed Ang-(1-7) effects on 66.1 cell viability in vitro. 66.1 cells were treated with vehicle, or increasing concentrations of Ang-(1-7) (1, 10, 100, or 1000 ng) for 24 hours, and an XTT cell viability assay was performed. As compared with vehicle-treated cells (relative absorbance $\pm \mathrm{SD}=$ $1.02 \pm 0.09)$, each of the 4 Ang-(1-7) treatments did not significantly change cell viability ( $1 \mathrm{ng}: 0.93 \pm 0.11 ; 10 \mathrm{ng}: 0.93 \pm$ 0.07; 100 ng: $0.78 \pm 0.11,1000$ ng: $0.93 \pm 0.13)$. Together, these data indicate that Ang-(1-7) at the doses/concentrations tested neither promotes cell proliferation nor causes cell death both in vivo and in vitro.

\subsection{Repeated dosing of Ang-(1-7) does not affect bone remodeling of mice with established cancer-induced bone pain}

Radiographic images of all chronically treated animals were taken on days $0,7,10$, and 14 after surgery to determine whether repeated Ang-(1-7) administration affected bone remodeling in mice with established CIBP (Fig. 7A). Day 14 images were scored by 3 blinded observers with the following scale (Fig. 7B): 0, healthy bone; 1, 1 to 3 lesions; 2, 4 to 6 lesions; 3, unicortical fracture; and 4, bicortical fractures. A healthy bone was defined as one without any visible lesions or fractures, and a lesion was defined as a dark hole-like spot below the epiphyseal plate. Although no animals experienced bicortical fractures, both saline and Ang-(1-7)-treated cancer-inoculated animals experienced unicortical fractures. Media animals (7 of 16) received scores of 0 . As another marker of bone remodeling, levels of CTX in the serum were quantified (Fig. 7C). Although cancer-inoculation significantly increased $(P<0.05, \mathrm{n}=3-4)$ CTX levels in the bone compared with both media controls, repeated Ang-(1-7) administration did not significantly alter CTX levels compared with the 66.1 saline-treated group. Overall, daily Ang-(1-7) administration in mice with established CIBP did not significantly influence bone remodeling of the ipsilateral femur.

\section{Discussion}

The RAS, widely known for its roles in blood pressure and fluid homeostasis, was recently implicated in several facets of metastatic bone disease including inflammation, angiogenesis, tumor cell proliferation, and migration. ${ }^{45,61}$ The $A T_{1}$ and $A T_{2}$ receptors are reportedly on nociceptive cells of the DRG and are speculated as playing a role in pain ${ }^{3,46,78}$; yet, the expression of the $\mathrm{AT}_{2}$ receptors on the DRG of mice TRPV1-lineage neurons using RNA-Seq transcriptome analysis demonstrated minimal expression. ${ }^{13}$ RNA-Seq analysis of the Mas1 receptor demonstrated a low amount in the rat and mouse DRG with a high expression in the hind paw, ${ }^{13}$ supporting the response seen in 

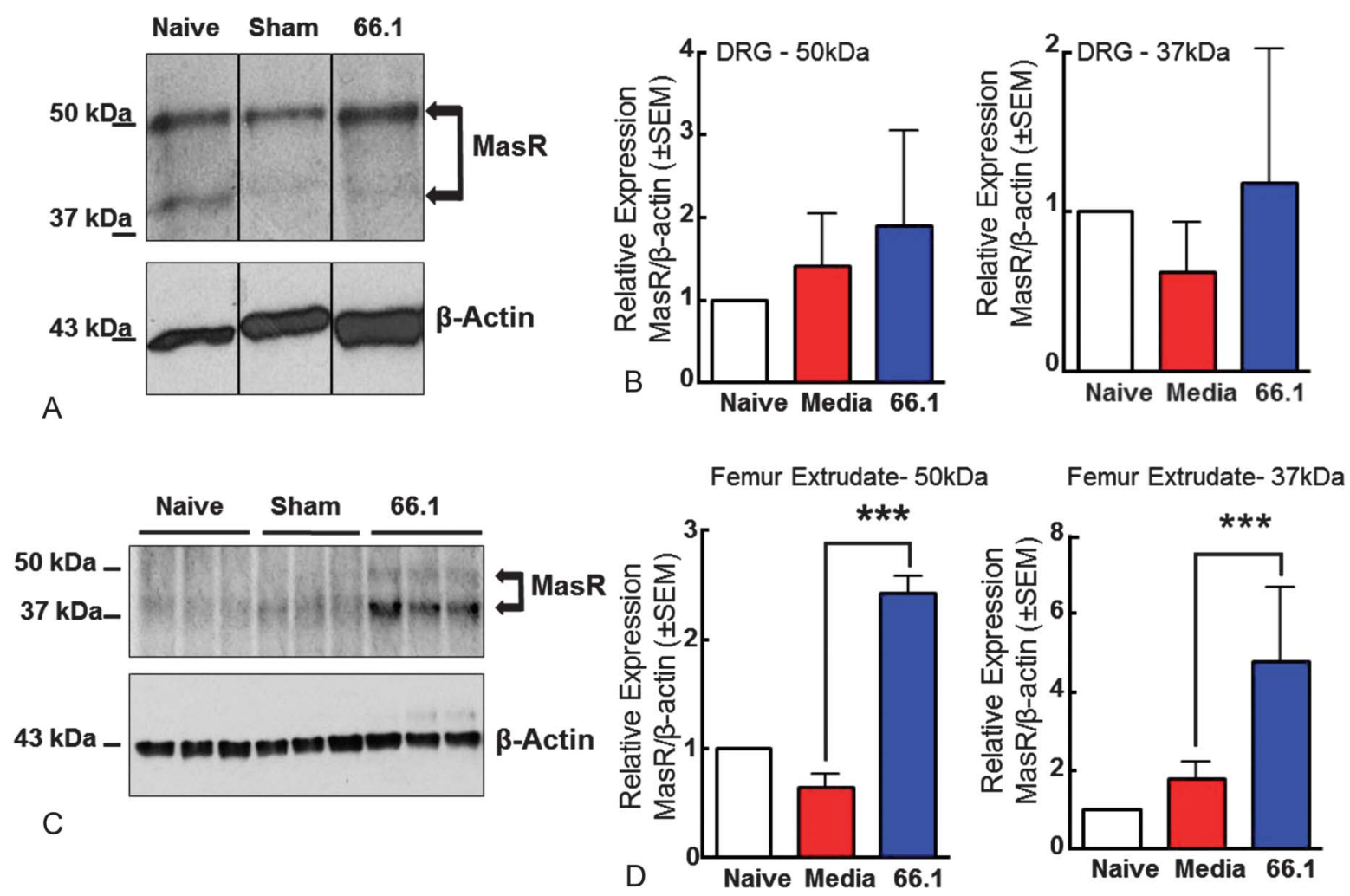

Figure 5. MasR is expressed in the dorsal root ganglion (DRG) and femur extrudate. (A) Ipsilateral DRG were harvested from naive, sham (media inoculated), or chronically treated 66.1-inoculated mice, homogenized, and probed for MasR expression through Western blotting. MasR is expressed in the DRG; MasR bands were observed at $\sim 50$ and $\sim 40 \mathrm{kDa}$ (B). Sham surgery (ie, media only) did not alter MasR expression levels in the DRG. 66.1 inoculation increased the expression of MasR in the ipsilateral DRG, although not statistically significant. $\beta$-actin serves as the loading control (pools of DRG from $n=3-5$ animals). (C) Ipsilateral bone marrow extrudate was harvested from naive, sham (media-inoculated), or cancer-inoculated mice and probed for MasR expression through Western blotting. MasR is expressed in the femur extrudates of mice. MasR bands were observed at $\sim 50$ and $\sim 40 \mathrm{kDa}$. (D) Sham surgery (ie, media only) did not alter MasR expression levels at $\sim 40$ or $\sim 50 \mathrm{kDa}$ in the femur extrudate. 66.1 inoculation significantly increased $(P<0.001)$ the expression of MasR in the ipsilateral femur extrudate. $\beta$-actin serves as the loading control (Pools of femur extrudate from $n=3-5$ mice).

these bone cancer studies. More importantly, the $\mathrm{AT}_{2}$-selective and orally active receptor antagonist, EMA401, demonstrated clinical efficacy in a double-blind, randomized, placebocontrolled, clinical trial of patients with postherpetic neuralgia. ${ }^{51}$ A similar $\mathrm{AT}_{2}$ selective antagonist has demonstrated significant analgesic activity in a rat model of neuropathic pain ${ }^{64,65}$ and a preclinical model of prostate cancer bone pain by an indirect mechanism of inhibiting NGF-TrkA in the DRG of fibers that innervate the cancer-inoculated tibia. ${ }^{37}$ In part, the inhibition by EMA401 of endogenous angiotensin $\|$ acting at $A T_{2}$ receptors resulting in the inhibition of pain suggests that endogenous angiotensin would further be metabolized to the Ang-(1-7) with increased access to the
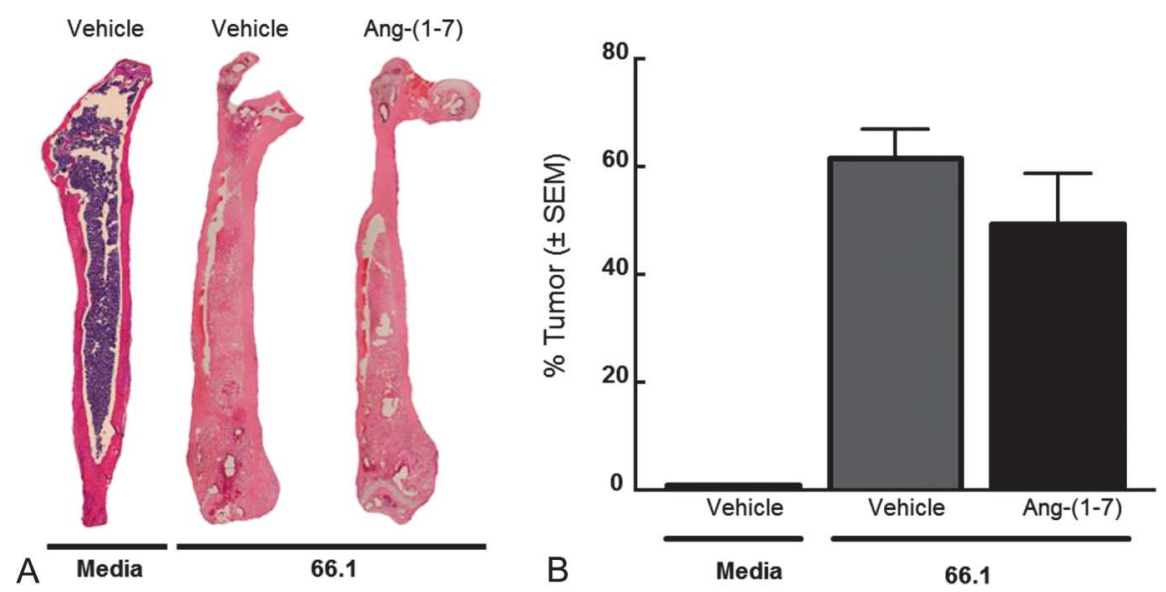

Figure 6. Repeated dosing of Ang-(1-7) does not alter tumor burden of mice with established cancer-induced bone pain. (A) Femurs were harvested from animals and stained with hematoxylin and eosin. The area of the bone containing cancer cells was quantified and presented as a \% tumor of the whole bone. (B) Repeated Ang-(1-7) administration did not significantly reduce the percent tumor of the bone $(P=0.3)$ compared with the saline-treated group. Values represent mean \pm $\mathrm{SEM}, \mathrm{n}=5$ to 11 per group. 
Media
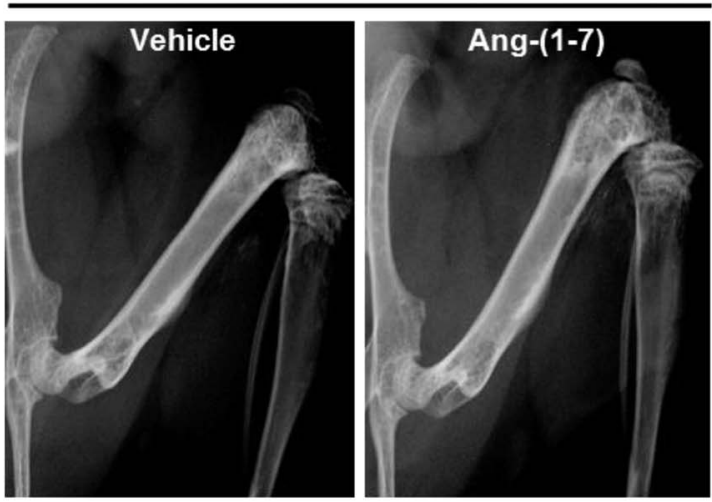

A

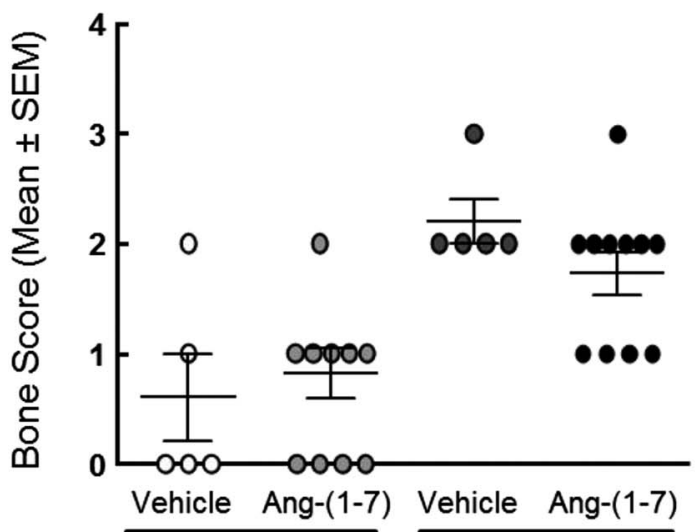

B

Media

66.1

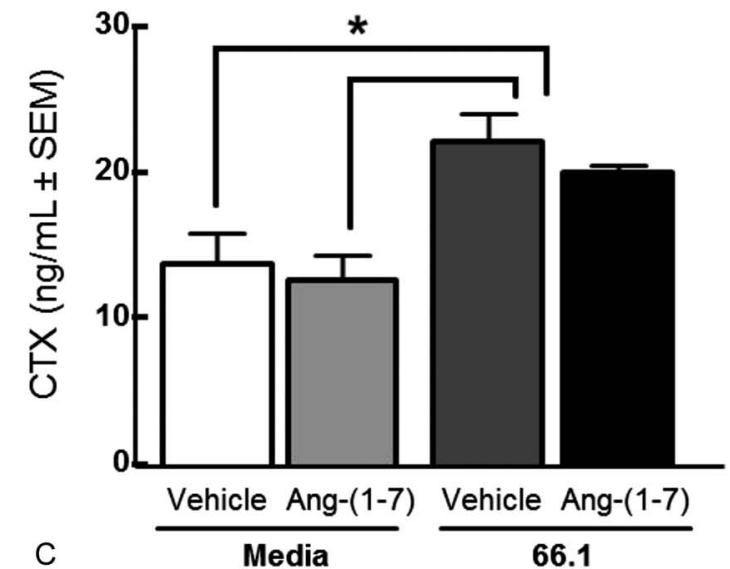

Figure 7. Repeated dosing of Ang-(1-7) does not affect bone remodeling of mice with established cancer-induced bone pain. (A) Representative day 14 radiographs of chronically treated animals. (B) Day 14 images were scored by 3 blinded observers with the following scale: 0 , healthy bone; 1 , 1 to 3 lesions; 2 , 4 to 6 lesions; 3, unicortical fracture; and 4, bicortical fractures. Both saline- and Ang-(1-7)-treated cancerous animals experienced unicortical fractures. (C) Levels of carboxy-terminal collagen crosslinks (CTX) in the serum were quantified as another measure of bone remodeling. Although cancer-inoculation significantly increased $(P<0.05)$ CTX levels in the bone compared with both media controls. Repeated Ang-(1-7) administration did not significantly alter CTX levels compared with the 66.1 saline-treated group.

Mas1 receptor possibly producing its analgesic effects through MasR activation vs $\mathrm{AT}_{2}$ based on our studies.

Despite implication of the RAS in metastatic disease and pain, few studies have investigated the MasR/Ang-(1-7) peptide fragment in CIBP. There is evidence that the Mas receptor increases mRNA and protein expression in corresponding DRG after chronic constriction injury to the sciatic nerve and that Ang(1-7) significantly inhibits neuropathic pain in chronic constriction injury. ${ }^{79}$ In a model of prostaglandin-induced hyperalgesia, Ang(1-7) dose-dependently attenuated behavioral signs of pain. ${ }^{7,9,41}$ Because of the inflammatory and neuropathic characteristics of bone cancer pain, we chose to investigate the utility of Ang-(1-7) in CIBP. Acute and chronic systemic administration of Ang-(1-7) significantly reduced the spontaneous pain behaviors associated with CIBP. Importantly, repeated administration attenuated CIBP without loss of efficacy after 7 days. However, we did not find any significant change in nesting behaviors with or without treatments, which suggests that nesting is not representative of possible anxiety or depression in mice with CIBP. The Mas receptor antagonist, A-779, significantly prevented the inhibition of guarding and flinching induced by Ang-(1-7) was significantly prevented by the Mas receptor antagonist, A-779. Furthermore, we found that the preadministration of an $A T_{1}$ receptor antagonist, Losartan, further alleviates CIBP, yet by itself had no significant effect. Although endogenous Ang-(1-7) has 60- to 100-fold greater selectivity for MasR over the $A T_{1}$ and $A T_{2}$ receptors, ${ }^{11,58}$ our results suggest that systemic Ang-(1-7) may bind at both MasR and $A T_{1}$, which implicates that strong binding at MasR may cause a significant antinociceptive effect whereas weak binding at $A T_{1}$ may cause Ang-(1-7) to mimic Ang II, resulting in pain. AT1 receptor blockers have been shown to increase angiotensin-converting enzyme 2 (ACE2), which is responsible for the production of endogenous Ang-(1-7), in line with acting at Mas receptors to reduce proinflammatory cytokines such as TNF- $\alpha$, IFN- $\gamma, \mathrm{IL}-1 \beta, \mathrm{IL}-6$ and increase of the antiinflammatory cytokine, IL-10. ${ }^{67-69}$ This juxtaposition of painrelieving and pain-causing actions of Ang-(1-7) implicates the full potential of the Ang-(1-7)/MasR axis in reducing CIBP. Additionally, it has been shown that the Mas-protooncogene has known interactions with the $A T_{1}$ receptors, but not the $A T_{2}$ receptor, further supporting our results. ${ }^{73}$ Use of Losartan might be additive in effect to Ang-(1-7) in CIBP because $A T_{1}$ antagonism inhibits Ang-(1-7) from acting similarly to Ang $\|$ at $A T_{1}$, thereby allowing Ang-(1-7) to bind primarily to MasR to significantly alleviate pain. Our results demonstrate that the $\mathrm{AT}_{2}$ antagonist, $\mathrm{PD} 123319$, did not attenuate the effects of Ang-(1-7) nor result in enhanced pain relief, which suggests that the $A T_{2}$ receptor may not play a role in CIBP. Our results further suggest that MasR is fully activated by exogenous Ang-(1-7) and cannot be further activated by residual breakdown of Ang II. 
If MasR is a valid therapeutic target for CIBP and the site of action for Ang-(1-7), one may expect changes in MasR expression within the nociceptive circuit and/or the bone-tumor microenvironment. Our data confirms that MasR is expressed in the DRG of naive mice, in accordance with a previous report of inflammatory pain, ${ }^{9}$ and in the femur extrudate. However, our 2 bands for MasR emerged at $\sim 50$ and $\sim 37 \mathrm{kDa}$; others show MasR at $37 \mathrm{kDa}$ in the retina, ${ }^{49} 49 \mathrm{kDa}$ in the skeletal muscle, ${ }^{53}$ and $83 \mathrm{kDa}$ in HEK293T cells. ${ }^{22}$ Such inconsistency in the molecular weight is currently unexplained in the literature. However, there are 3 different sites of glycosylation on MasR, which may help to explain the differences in the molecular weight. Although repeated Ang-(1-7) administration did not significantly alter the expression of MasR in the DRG or femur extrudate, its presence in the DRG and femur extrudate in our model supports the role of Ang-(1-7)/MasR as a potential therapeutic target for CIBP. Repeated Ang-(1-7) dosing does not significantly alter MasR expression in the DRG containing soma of fibers innervating the bone-tumor microenvironment, supporting our lack of analgesic tolerance over the treatment paradigm.

Our data indicate that Ang-(1-7) at the Mas receptor is inhibiting pain through the tumor-nociceptor microenvironment and not through the tumor-bone environment because Ang-(1-7) did not significantly change the tumor-induced degradation of the bone. Unlike studies using compounds that modulate bone wasting $^{27,29}$ and the pain that may come from altered osteoclast activity, our chronic studies with Ang-(1-7) did not significantly decrease bone loss. The chronic treatment with Ang-(1-7) did not significantly alter tumor proliferation, which further suggests that the analgesic effect is directly toward inhibiting nociceptive activation and not due to changes in tumor burden.

The exact mechanisms by which Ang-(1-7)/MasR exerts its antinociceptive effect are unknown. In addition to modulating proinflammatory factors ${ }^{61}$ and regulating transcription of IL-16, an anti-inflammatory cytokine in the tumor-bone microenvironment, Ang-(1-7)/MasR activation of the MAPK pathway may decrease transcription of norepinephrine transporters, leading to an increase of norepinephrine in the synaptic cleft $^{41}$ and/or stimulating endogenous norepinephrine release that activates peripheral adrenoceptors inducing antinociception. ${ }^{7}$ Moreover, Ang-(1-7) binding to MasR may inhibit phosphorylation of p38 MAPK. ${ }^{41}$ Phosphorylation of spinal p38 MAPK has been observed in chronic injury, ${ }^{77}$ and therefore a decrease in phospho-p38 MAPK in chronic injury models such as CIBP may prove to yield antinociceptive effect. MasR activation by Ang-(1-7) can activate nitric oxide synthase, increasing intracellular $\mathrm{NO}^{8}$ to further increase intracellular levels of cyclic GMP (cGMP). cGMP production leads to the activation of ATP-dependent potassium channels, thereby hyperpolarizing the neuron, ${ }^{1,2,50}$ in addition to blocking voltage-gated calcium channels that will slow or block neurotransmitter release. Together, the actions of Ang-(1-7)/MasR on cGMP levels can suppress nociception through a decrease in neuronal firing of nociceptive fibers. The mechanisms that result in metastatic bone cancer pain have only recently been investigated an include significant increases in cytokines, ${ }^{31}$ extracellular glutamate, ${ }^{62}$ and nerve growth factor/TrkA-induced, as well as neuronal sprouting of sensory and sympathetic fibers. ${ }^{18-20,32}$ Yet, there are no studies that have investigated whether Ang1-7/MasR alter neuronal sprouting or spontaneous activity of sensory neurons. Finally, the Mas receptor can dimerize with the AT1 receptor, ${ }^{22,56}$ where it acts as an antagonist to the receptor. In doing so, such dimerization prevents Ang II from binding, resulting in the possible inhibition of its pronociceptive effects. In a similar fashion, we have shown that the AT1 receptor antagonist is useful in inhibiting Ang-(1-7) from binding in place of Ang II to optimize the antinociceptive effects of this peptide. Further research is warranted to elucidate the exact mechanism by which the Ang(1-7)/MasR axis is acting to reduce CIBP.

Our results support further investigation of the Mas receptor as a target for cancer therapeutics. Recently, it has been discussed that the GPCRs of the RAS play a significant role in breast cancer, ${ }^{52}$ and most specifically the Ang-(1-7)/MasR axis, as it has been shown to be protective against cancer. Stimulation of MasR through Ang-(1-7) treatment has been shown to have antiproliferative effects against tumor growth ${ }^{12,24,34}$ without major effects. Ang-(1-7) treatment in a metastatic prostate cancer model has been shown to lead to a reduction of osteoclastogenesis, ${ }^{23}$ suggesting that Ang-(1-7) prevents the formation of osteolytic lesions. Although our sustained studies using a syngeneic murine model of breast cancer did not result in a significant reduction in tumor proliferation or attenuation in tumor-induced bone loss, further investigation of doses, pharmacokinetics, and receptor selectivity is further needed to identify tumor survival in the bone-tumor microenvironment and the mechanism(s) of pain inhibition. Thus, the use of Ang-(1-7) in treating CIBP is a highly favorable and a safe alternative or adjuvant therapeutic to the current clinical treatments. Together, our data support the use of Ang-(1-7), perhaps in conjunction with Losartan, as an alternative therapeutic strategy for CIBP.

\section{Conflict of interest statement}

The authors have no conflicts of interest to declare.

This work was supported by the College of Medicine at the University of Arizona and by $\mathrm{NIH}-\mathrm{NCl}$ grant number $\mathrm{R} 01$ CA142115-01.

\section{Acknowledgements}

All authors contributed to the data collection, interpretation, and writing of this manuscript.

\section{Article history:}

Received 15 June 2016

Received in revised form 4 August 2016

Accepted 9 August 2016

Available online 18 August 2016

\section{References}

[1] Alves D, Duarte I. Involvement of ATP-sensitive $K(+)$ channels in the peripheral antinociceptive effect induced by dipyrone. Eur J Pharmacol 2002;444:47-52.

[2] Alves DP, Tatsuo MA, Leite R, Duarte ID. Diclofenac-induced peripheral antinociception is associated with ATP-sensitive $\mathrm{K}+$ channels activation. Life Sci 2004;74:2577-91.

[3] Anand U, Facer P, Yiangou Y, Sinisi M, Fox M, McCarthy T, Bountra C, Korchev YE, Anand P. Angiotensin II type 2 receptor (AT2 R) localization and antagonist-mediated inhibition of capsaicin responses and neurite outgrowth in human and rat sensory neurons. Eur J Pain 2013;17: 1012-26.

[4] Birnbaum HG, White AG, Schiller M, Waldman T, Cleveland JM, Roland CL. Societal costs of prescription opioid abuse, dependence, and misuse in the United States. Pain Med 2011;12:657-67.

[5] Blankley CJ, Hodges JC, Klutchko SR, Himmelsbach RJ, Chucholowski A, Connolly CJ, Neergaard SJ, Van Nieuwenhze MS, Sebastian A, Quin J III, Essenburg AD, Cohen DM. Synthesis and structure-activity relationships of a novel series of non-peptide angiotensin II receptor binding inhibitors specific for the AT2 subtype. J Med Chem 1991;34:3248-60.

[6] Carini DJ, Duncia JV, Aldrich PE, Chiu AT, Johnson AL, Pierce ME, Price WA, Santella JB III, Wells GJ, Wexler RR, Wong PC, Yoo SE, Timmermans PBMWM. Nonpeptide angiotensin II receptor antagonists: the discovery 
of a series of $\mathrm{N}$-(biphenylylmethyl) imidazoles as potent, orally active antihypertensives. J Med Chem 1991;34:2525-47.

[7] Castor MG, Santos RA, Duarte ID, Romero TR. Angiotensin-(1-7) through Mas receptor activation induces peripheral antinociception by interaction with adrenoreceptors. Peptides 2015;69:80-5.

[8] Costa A, Galdino G, Romero T, Silva G, Cortes S, Santos R, Duarte I. Ang(1-7) activates the NO/cGMP and ATP-sensitive K+ channels pathway to induce peripheral antinociception in rats. Nitric Oxide 2014;37:11-16.

[9] Costa AC, Becker LK, Moraes ER, Romero TR, Guzzo L, Santos RA, Duarte ID. Angiotensin-(1-7) induces peripheral antinociception through mas receptor activation in an opioid-independent pathway. Pharmacology 2012;89:137-44

[10] Dursteler-MacFarland KM, Kowalewski R, Bloch N, Wiesbeck GA, Kraenzlin ME, Stohler R. Patients on injectable diacetylmorphine maintenance have low bone mass. Drug Alcohol Rev 2011;30:577-82.

[11] Ferreira AJ, Santos RA. Cardiovascular actions of angiotensin-(1-7). Braz J Med Biol Res 2005;38:499-507.

[12] Gallagher PE, Tallant EA. Inhibition of human lung cancer cell growth by angiotensin-(1-7). Carcinogenesis 2004;25:2045-52.

[13] Goswami SC, Mishra SK, Maric D, Kaszas K, Gonnella GL, Clokie SJ, Kominsky HD, Gross JR, Keller JM, Mannes AJ, Hoon MA, ladarola MJ. Molecular signatures of mouse TRPV1-lineage neurons revealed by RNASeq transcriptome analysis. J Pain 2014;15:1338-59.

[14] Grey A, Rix-Trott K, Horne A, Gamble G, Bolland M, Reid IR. Decreased bone density in men on methadone maintenance therapy. Addiction 2011;106:349-54.

[15] Gupta K, Kshirsagar S, Chang L, Schwartz R, Law PY, Yee D, Hebbel RP. Morphine stimulates angiogenesis by activating proangiogenic and survival-promoting signaling and promotes breast tumor growth. Cancer Res 2002;62:4491-8.

[16] Hutchinson MR, Zhang Y, Shridhar M, Evans JH, Buchanan MM, Zhao TX, Slivka PF, Coats BD, Rezvani N, Wieseler J, Hughes TS, Landgraf KE, Chan S, Fong S, Phipps S, Falke JJ, Leinwand LA, Maier SF, Yin H, Rice KC, Watkins LR. Evidence that opioids may have toll-like receptor 4 and MD-2 effects. Brain Behav Immun 2010;24:83-95.

[17] Inagami T. A memorial to Robert Tiegerstedt: the centennial of renin discovery. Hypertension 1998;32:953-7.

[18] Jimenez-Andrade JM, Bloom AP, Stake Jl, Mantyh WG, Taylor RN, Freeman KT, Ghilardi JR, Kuskowski MA, Mantyh PW. Pathological sprouting of adult nociceptors in chronic prostate cancer-induced bone pain. J Neurosci 2010;30:14649-56.

[19] Jimenez-Andrade JM, Ghilardi JR, Castaneda-Corral G, Kuskowski MA, Mantyh PW. Preventive or late administration of anti-NGF therapy attenuates tumor-induced nerve sprouting, neuroma formation, and cancer pain. PAIN 2011;152:2564-74.

[20] Jimenez Andrade JM, Mantyh P. Cancer pain: from the development of mouse models to human clinical trials. In: Translational Pain Research: From Mouse to Man. Boca Raton, FL: CRC Press/Taylor \& Francis; 2010. Chapter 4.

[21] King T, Vardanyan A, Majuta L, Melemedjian O, Nagle R, Cress AE, Vanderah TW, Lai J, Porreca F. Morphine treatment accelerates sarcoma-induced bone pain, bone loss, and spontaneous fracture in a murine model of bone cancer. PAIN 2007;132:154-68.

[22] Kostenis E, Milligan G, Christopoulos A, Sanchez-Ferrer CF, HeringerWalther S, Sexton PM, Gembardt F, Kellett E, Martini L, Vanderheyden P, Schultheiss HP, Walther T. G-protein-coupled receptor Mas is a physiological antagonist of the angiotensin II type 1 receptor. Circulation 2005;111: 1806-13.

[23] Krishnan B, Smith TL, Dubey P, Zapadka ME, Torti FM, Willingham MC, Tallant EA, Gallagher PE. Angiotensin-(1-7) attenuates metastatic prostate cancer and reduces osteoclastogenesis. Prostate 2013;73:71-82.

[24] Krishnan B, Torti FM, Gallagher PE, Tallant EA. Angiotensin-(1-7) reduces proliferation and angiogenesis of human prostate cancer xenografts with a decrease in angiogenic factors and an increase in sFlt-1. Prostate 2013; 73:60-70.

[25] Lakshmanan AP, Thandavarayan RA, Watanabe K, Sari FR, Meilei $H$, Giridharan W, Sukumaran V, Soetikno V, Arumugam S, Suzuki K, Kodama M. Modulation of AT-1R/MAPK cascade by an olmesartan treatment attenuates diabetic nephropathy in streptozotocin-induced diabetic mice. Mol Cell Endocrinol 2012;348:104-11.

[26] Lennon FE, Mirzapoiazova T, Mambetsariev B, Poroyko VA, Salgia R, Moss J, Singleton PA. The Mu opioid receptor promotes opioid and growth factorinduced proliferation, migration and Epithelial Mesenchymal Transition (EMT) in human lung cancer. PLoS One 2014;9:e91577.

[27] Lozano-Ondoua AN, Hanlon KE, Symons-Liguori AM, Largent-Milnes TM, Havelin JJ, Ferland HL III, Chandramouli A, Owusu-Ankomah M, Nikolich-Zugich T, Bloom AP, Jimenez-Andrade JM, King T, Porreca F, Nelson MA, Mantyh PW, Vanderah TW. Disease modification of breast cancer-induced bone remodeling by cannabinoid 2 receptor agonists. J Bone Miner Res 2013;28:92-107.

[28] Lozano-Ondoua AN, Symons-Liguori AM, Vanderah TW. Cancerinduced bone pain: mechanisms and models. Neurosci Lett 2013;557 (pt A):52-9.

[29] Lozano-Ondoua AN, Wright C, Vardanyan A, King T, Largent-Milnes TM, Nelson M, Jimenez-Andrade JM, Mantyh PW, Vanderah TW. A cannabinoid 2 receptor agonist attenuates bone cancer-induced pain and bone loss. Life Sci 2010;86:646-53.

[30] Luger NM, Honore P, Sabino MA, Schwei MJ, Rogers SD, Mach DB, Clohisy DR, Mantyh PW. Osteoprotegerin diminishes advanced bone cancer pain. Cancer Res 2001;61:4038-47.

[31] Mach DB, Rogers SD, Sabino MC, Luger NM, Schwei MJ, Pomonis JD, Keyser CP, Clohisy DR, Adams DJ, O'Leary P, Mantyh PW. Origins of skeletal pain: sensory and sympathetic innervation of the mouse femur. Neuroscience 2002;113:155-66.

[32] Mantyh WG, Jimenez-Andrade JM, Stake JI, Bloom AP, Kaczmarska MJ, Taylor RN, Freeman KT, Ghilardi JR, Kuskowski MA, Mantyh PW. Blockade of nerve sprouting and neuroma formation markedly attenuates the development of late stage cancer pain. Neuroscience 2010;171: 588-98.

[33] Mehta PK, Griendling KK. Angiotensin II cell signaling: physiological and pathological effects in the cardiovascular system. Am J Physiol Cell Physiol 2007:292:C82-97.

[34] Menon J, Soto-Pantoja DR, Callahan MF, Cline JM, Ferrario CM, Tallant EA, Gallagher PE. Angiotensin-(1-7) inhibits growth of human lung adenocarcinoma xenografts in nude mice through a reduction in cyclooxygenase-2. Cancer Res 2007;67:2809-15.

[35] Mercadante S. Malignant bone pain: pathophysiology and treatment. PAIN 1997;69:1-18.

[36] Mundy GR. Pathophysiology of cancer-associated hypercalcemia. Semin Oncol 1990;17(2 suppl 5):10-15.

[37] Muralidharan A, Wyse BD, Smith MT. Analgesic efficacy and mode of action of a selective small molecule angiotensin II type 2 receptor antagonist in a rat model of prostate cancer-induced bone pain. Pain Med 2014; 15:93-110.

[38] Myles PS, Peyton P, Silbert B, Hunt J, Rigg JR, Sessler DI; ANZCA Trials Group Investigators. Perioperative epidural analgesia for major abdominal surgery for cancer and recurrence-free survival: randomised trial. BMJ 2011;342:d1491.

[39] Nagae M, Hiraga T, Yoneda T. Acidic microenvironment created by osteoclasts causes bone pain associated with tumor colonization. J Bone Miner Metab 2007;25:99-104.

[40] Negus SS, Neddenriep B, Altarifi AA, Carroll FI, Leitl MD, Miller LL. Effects of ketoprofen, morphine, and kappa opioids on pain-related depression of nesting in mice. PAIN 2015;156:1153-60.

[41] Nemoto W, Ogata Y, Nakagawasai O, Yaoita F, Tadano T, Tan-No K. Angiotensin (1-7) prevents angiotensin II-induced nociceptive behaviour via inhibition of p38 MAPK phosphorylation mediated through spinal Mas receptors in mice. Eur J Pain 2014;18:1471-9.

[42] O'Connell JX, Nanthakumar SS, Nielsen GP, Rosenberg AE. Osteoid osteoma: the uniquely innervated bone tumor. Mod Pathol 1998;11: 175-80.

[43] Ohshima K, Mogi M, Nakaoka H, Iwanami J, Min LJ, Kanno H, Tsukuda K, Chisaka T, Bai HY, Wang XL, Ogimoto A, Higaki J, Horiuchi M. Possible role of angiotensin-converting enzyme 2 and activation of angiotensin II type 2 receptor by angiotensin-(1-7) in improvement of vascular remodeling by angiotensin II type 1 receptor blockade. Hypertension 2014;63: e53-59.

[44] Papinska AM, Mordwinkin NM, Meeks CJ, Jadhav SS, Rodgers KE. Angiotensin-(1-7) administration benefits cardiac, renal and progenitor cell function in db/db mice. Br J Pharmacol 2015;172:4443-53.

[45] Passos-Silva DG, Verano-Braga T, Santos RA. Angiotensin-(1-7): beyond the cardio-renal actions. Clin Sci (Lond) 2013;124:443-56.

[46] Pavel J, Tang H, Brimijoin S, Moughamian A, Nishioku T, Benicky J, Saavedra JM. Expression and transport of Angiotensin II AT1 receptors in spinal cord, dorsal root ganglia and sciatic nerve of the rat. Brain Res 2008;1246:111-22

[47] Perez-Castrillon JL, Olmos JM, Gomez JJ, Barrallo A, Riancho JA, Perera L, Valero C, Amado JA, Gonzalez-Macias J. Expression of opioid receptors in osteoblast-like MG-63 cells, and effects of different opioid agonists on alkaline phosphatase and osteocalcin secretion by these cells. Neuroendocrinology 2000;72:187-94.

[48] Portenoy RK, Lesage P. Management of cancer pain. Lancet 1999;353: 1695-700

[49] Prasad T, Verma A, Li Q. Expression and cellular localization of the Mas receptor in the adult and developing mouse retina. Mol Vis 2014;20: 1443-55. 
[50] Reis GM, Pacheco D, Perez AC, Klein A, Ramos MA, Duarte ID. Opioid receptor and NO/cGMP pathway as a mechanism of peripheral antinociceptive action of the cannabinoid receptor agonist anandamide. Life Sci 2009;85:351-6.

[51] Rice AS, Dworkin RH, McCarthy TD, Anand P, Bountra C, McCloud PI, Hill J, Cutter G, Kitson G, Desem N, Raff M; EMA401-003 Study Group. EMA401, an orally administered highly selective angiotensin II type 2 receptor antagonist, as a novel treatment for postherpetic neuralgia: a randomised, double-blind, placebo-controlled phase 2 clinical trial. Lancet 2014;383:1637-47.

[52] Rodrigues-Ferreira S, Nahmias C. G-protein coupled receptors of the renin-angiotensin system: new targets against breast cancer? Front Pharmacol 2015;6:24.

[53] Sabharwal R, Cicha MZ, Sinisterra RD, De Sousa FB, Santos RA, Chapleau MW. Chronic oral administration of Ang-(1-7) improves skeletal muscle, autonomic and locomotor phenotypes in muscular dystrophy. Clin Sci (Lond) 2014;127:101-9.

[54] Sabino MA, Luger NM, Mach DB, Rogers SD, Schwei MJ, Mantyh PW. Different tumors in bone each give rise to a distinct pattern of skeletal destruction, bone cancer-related pain behaviors and neurochemical changes in the central nervous system. Int J Cancer 2003;104:550-8.

[55] Sabino MA, Mantyh PW. Pathophysiology of bone cancer pain. J Support Oncol 2005;3:15-24.

[56] Santos EL, Reis RI, Silva RG, Shimuta Sl, Pecher C, Bascands JL, Schanstra JP, Oliveira L, Bader M, Paiva AC, Costa-Neto CM, Pesquero JB. Functional rescue of a defective angiotensin II AT1 receptor mutant by the Mas protooncogene. Regul Pept 2007;141:159-67.

[57] Santos RA, Haibara AS, Campagnole-Santos MJ, Simoes e Silva AC, Paula RD, Pinheiro SV, Leite MF, Lemos VS, Silva DM, Guerra MT, Khosla MC. Characterization of a new selective antagonist for angiotensin-(1-7), D-pro7-angiotensin-(1-7). Hypertension 2003;41(3 pt 2):737-43.

[58] Santos RA, Simoes e Silva AC, Maric C, Silva DM, Machado RP, de Buhr I, Heringer-Walther S, Pinheiro SV, Lopes MT, Bader M, Mendes EP, Lemos VS, Campagnole-Santos MJ, Schultheiss HP, Speth R, Walther T. Angiotensin-(1-7) is an endogenous ligand for the $G$ protein-coupled receptor Mas. Proc Natl Acad Sci U S A 2003;100:8258-63.

[59] Schwei MJ, Honore P, Rogers SD, Salak-Johnson JL, Finke MP, Ramnaraine ML, Clohisy DR, Mantyh PW. Neurochemical and cellular reorganization of the spinal cord in a murine model of bone cancer pain. J Neurosci 1999;19:10886-97.

[60] Sharma A, Cohen HW, Freeman R, Santoro N, Schoenbaum EE. Prospective evaluation of bone mineral density among middle-aged HIVinfected and uninfected women: Association between methadone use and bone loss. Maturitas 2011;70:295-301.

[61] Simoes e Silva AC, Silveira KD, Ferreira AJ, Teixeira MM. ACE2, angiotensin-(1-7) and Mas receptor axis in inflammation and fibrosis. $\mathrm{Br}$ J Pharmacol 2013;169:477-92.

[62] Slosky LM, BassiriRad NM, Symons AM, Thompson M, Doyle T, Forte BL, Staatz WD, Bui L, Neumann WL, Mantyh PW, Salvemini D, Largent-Milnes TM, Vanderah TW. The cystine/glutamate antiporter system xc- drives breast tumor cell glutamate release and cancer-induced bone pain. PAIN; 2016. Epub ahead of print. DOI: 10.1097/j.pain.0000000000000681.

[63] Slosky LM, Largent-Milnes TM, Vanderah TW. Use of animal models in understanding cancer-induced bone pain. Cancer Growth Metastasis 2015;8(suppl 1):47-62.

[64] Smith MT, Woodruff TM, Wyse BD, Muralidharan A, Walther T. A small molecule angiotensin II type 2 receptor (AT(2)R) antagonist produces analgesia in a rat model of neuropathic pain by inhibition of p38 mitogenactivated protein kinase (MAPK) and p44/p42 MAPK activation in the dorsal root ganglia. Pain Med 2013;14:1557-68.
[65] Smith MT, Wyse BD, Edwards SR. Small molecule angiotensin II type 2 receptor (AT(2)R) antagonists as novel analgesics for neuropathic pain: comparative pharmacokinetics, radioligand binding, and efficacy in rats. Pain Med 2013:14:692-705.

[66] Stevens CW, Aravind S, Das S, Davis RL. Pharmacological characterization of LPS and opioid interactions at the toll-like receptor 4. $\mathrm{Br} J$ Pharmacol 2013;168:1421-9

[67] Sukumaran V, Veeraveedu PT, Gurusamy N, Lakshmanan AP, Yamaguchi K, Ma M, Suzuki K, Kodama M, Watanabe K. Telmisartan acts through the modulation of ACE-2/ANG 1-7/mas receptor in rats with dilated cardiomyopathy induced by experimental autoimmune myocarditis. Life Sci 2012;90:289-300.

[68] Sukumaran V, Veeraveedu PT, Gurusamy N, Lakshmanan AP, Yamaguchi K, Ma M, Suzuki K, Nagata M, Takagi R, Kodama M, Watanabe K. Olmesartan attenuates the development of heart failure after experimental autoimmune myocarditis in rats through the modulation of ANG 1-7 mas receptor. Mol Cell Endocrinol 2012;35:208-19.

[69] Sukumaran V, Veeraveedu PT, Gurusamy N, Yamaguchi K, Lakshmanan AP, Ma M, Suzuki K, Kodama M, Watanabe K. Cardioprotective effects of telmisartan against heart failure in rats induced by experimental autoimmune myocarditis through the modulation of angiotensin-converting enzyme-2/ angiotensin 1-7/mas receptor axis. Int J Biol Sci 2011;7:1077-92.

[70] Tronvik E, Stovner LJ. Role of angiotensin modulation in primary headaches. Curr Pain Headache Rep 2014:18:417.

[71] Vanderah TW, Largent-Milnes T, Lai J, Porreca F, Houghten RA, Menzaghi F, Wisniewski K, Stalewski J, Sueiras-Diaz J, Galyean R, Schteingart C, Junien JL, Trojnar J, Riviere PJ. Novel D-amino acid tetrapeptides produce potent antinociception by selectively acting at peripheral kappa-opioid receptors. Eur J Pharmacol 2008;583:62-72.

[72] Vermeirsch H, Nuydens RM, Salmon PL, Meert TF. Bone cancer pain model in mice: evaluation of pain behavior, bone destruction and morphine sensitivity. Pharmacol Biochem Behav 2004;79:243-51.

[73] von Bohlen und Halbach O, Walther T, Bader M, Albrecht D. Interaction between mas and the angiotensin AT1 receptor in the amygdala. J Neurophysiol 2000;83:2012-21.

[74] Walser TC, Rifat S, MaX, Kundu N, Ward C, Goloubeva O, Johnson MG, Medina JC, Collins TL, Fulton AM. Antagonism of CXCR3 inhibits lung metastasis in a murine model of metastatic breast cancer. Cancer Res 2006;66:7701-7.

[75] Wang X, Loram LC, Ramos K, de Jesus AJ, Thomas J, Cheng K, Reddy A, Somogyi AA, Hutchinson MR, Watkins LR, Yin H. Morphine activates neuroinflammation in a manner parallel to endotoxin. Proc Natl Acad SciUS A 2012;109:6325-30.

[76] WHO. Cancer Pain Relief. Geneva: World Health Organziation, 1998.

[77] Xu L, Huang Y, Yu X, Yue J, Yang N, Zuo P. The influence of p38 mitogen-activated protein kinase inhibitor on synthesis of inflammatory cytokine tumor necrosis factor alpha in spinal cord of rats with chronic constriction injury. Anesth Analg 2007;105:1838-44, Table of contents.

[78] Yang Y, Wu H, Yan JQ, Song ZB, Guo QL. Tumor necrosis factoralpha inhibits angiotensin II receptor type 1 expression in dorsal root ganglion neurons via beta-catenin signaling. Neuroscience 2013;248: 383-91.

[79] Zhao Y, Qin Y, Liu T, Hao D. Chronic nerve injury-induced Mas receptor expression in dorsal root ganglion neurons alleviates neuropathic pain. Exp Ther Med 2015;10:2384-8.

[80] Zylla D, Gourley BL, Vang D, Jackson S, Boatman S, Lindgren B, Kuskowski MA, Le C, Gupta K, Gupta P. Opioid requirement, opioid receptor expression, and clinical outcomes in patients with advanced prostate cancer. Cancer 2013;119:4103-10. 